\title{
Conciencia de clase en la Central Unitaria de Trabajadores y subordinación de clase en la democratización chilena (1990-1996)
}

Class consciousness in the Central Unitaria de Trabajadores and class subordination in the Chilean democratization (1990-1996)

Gabriel A. ASTUDILL01

Investigador independiente, Chile

astudillolar.g@gmail.com

\section{Resumen}

El presente artículo aborda la subordinación de los sectores populares en Chile durante los años de democratización, caracterizados como un contexto de alta desigualdad. Para ello se analiza el tipo de conciencia de clase presente en la Central Unitaria de Trabajadores - principal organización de la clase trabajadora- respecto de la identidad de clase, de los intereses materiales y de la reflexión sobre la estructura social. Se identifica allí un tipo de conciencia de clase que se propone denominar como hipoconflictiva, caracterizada por la evasión del conflicto entre capital y trabajo, la idea de que coexisten intereses contradictorios e intereses compartidos entre propietarios y asalariados, y una reflexión sobre la estructura social chilena que combina elementos de crítica y de justificación del modelo económico neoliberal. La propuesta de este trabajo es entender que la conciencia es producto de las experiencias de clase con la influencia ideológica de los partidos que dirigen la organización sindical, lo que tiene amplias consecuencias en el marco teórico-moral desde el cual la CUT juzga las experiencias de clase y desarrolla orientaciones de acción colectiva.

Palabras clave: Conciencia de classe; Trabajadores; Desigualdad; Conflictividad social.

1 Sociólogo chileno.

Gabriel A. Astudillo

Conciencia de clase en la Central Unitaria de Trabajadores y subordinación de clase en la democratización chilena (1990-1996)

Sur y Tiempo. Revista de Historia de América, №4, julio-diciembre 2021, pp. 90-117.

ISSN 2452-574X

DOI: $10.22370 /$ syt.2021.4.2914 


\begin{abstract}
This article explore the subordination of popular sectors in Chile during the years of democratization, characterized as a context of high inequality. To this purpose it's analyzed the type of class consciousness present in the Central Unitaria de Trabajadores - main organization of the working class- regarding class identity, material interests and reflection on the social structure. It's identified a type of class consciousness that is proposed to be called hypoconflictive, characterized by the avoidance of the conflict between capital and labor, the idea that contradictory interests and shared interests coexist between owners and employees, and a reflection on the Chilean social structure that combines elements of criticism and justification of the neoliberal economic model. The proposal of this work is to understand that consciousness is the product of class experiences with the ideological influence of the parties that lead the union organization, which has broad consequences in the theoretical-moral framework from which CUT judges class experiences, and develops guidelines for collective action.
\end{abstract}

Keywords: Class consciousness; Working class; Inequality; Social Conflict.

\title{
1. Introducción: desigualdad y conflictividad social
}

A lo largo del siglo XX en Chile, la desigualdad fue uno de los principales temas que articularon tanto a los movimientos sociales como el sistema de partidos. Desde los motines populares a comienzos de siglo (Garcés, 2003), pasando por el proyecto político de la Central Única de Trabajadores fundada en 1953 (Gaudichaud, 2005), hasta las protestas contra la dictadura convocadas por el Comando Nacional de Trabajadores (Araya, 2014; De la Maza y Garcés, 1985; Rojas, 2011; Manzano, 2014) había un reclamo explícito contra la desigualdad -aunque con distintas formas y grados de elaboración-, el cual motivaba la organización y la movilización.

En el mismo sentido, durante la primera mitad del siglo nacieron y se desarrollaron los partidos Comunista y Socialista, anclados en los sectores populares y la clase trabajadora organizada (Faletto y Ruiz, 1970). En ellos el marxismo se convirtió en la arquitectura teórica y moral desde la cual interpretar la sociedad, desarrollar orientaciones de acción de carácter conflictivo, y proponer proyectos de sociedad fuera de las relaciones capitalistas, precisamente como una respuesta al problema fundamental de la desigualdad.

Al término de la dictadura militar cambia radicalmente la problematización de la desigualdad que hacen los partidos que condujeron la democratización y que asumen los primeros gobiernos civiles. El Partido Socialista y la Democracia 
Cristiana dejan de lado las críticas al sistema capitalista -fundamentadas en la cuestión de la desigualdad-, para adoptar dentro de su propio ideario un neoliberalismo que ha sido calificado como corregido (Garretón, 2012), abandonando la pretensión de construir estructuras sociales de carácter comunitario o socialista.

Esto se tradujo en que los gobiernos de la Concertación dieron continuidad al modelo económico implementado por la dictadura. Si bien autores afines a esta coalición han sostenido que el complemento del mercado mediante una acción estatal que califican como decidida a mejorar las condiciones de vida de los sectores más vulnerables, es algo que no cabe calificar como modelo neoliberal (Garretón, 2012; Ffrench-Davis, 2003), otros autores han argumentado que las políticas sociales focalizadas no mitigan las consecuencias de desigualdad para la población, y tampoco alteran la centralidad del mercado y la empresa privada, siendo éstos los aspectos definitorios del neoliberalismo (Moulián, 1997; Ruiz y Boccardo, 2014).

En ese sentido, los gobiernos de la Concertación no abordaron explícitamente el tema de la desigualdad, sino el de la pobreza (Espinoza, 2012), para lo cual plantearon políticas sociales focalizadas, que tenían como objetivo garantizar un nivel de subsistencia mínimo (Raczynski, 1995). Ello tendría como consecuencia el mantenimiento de altos niveles de desigualdad en la década de los 90.

Según datos de la encuesta CASEN, el coeficiente de Gini sube desde 0,57 en 1990 a 0,58 en 2000 (Ministerio de Desarrollo Social, 2012). Alvaredo, Atria, Flores, Mayer y Sanhueza (2016), basados en datos de impuestos internos, muestran que los ingresos del 0,01\% más rico se habrían visto inalterados desde 1990 en adelante, mientras que Larrañaga (2001) demuestra que la desigualdad aumenta en el periodo neoliberal, sin diferencia significativa entre las aplicaciones que hicieron de éste la dictadura o la Concertación.

En ese contexto, la impugnación a la desigualdad generada por el modelo económico durante la dictadura fue uno, entre otros, de los reclamos que estaban a la base de las protestas contra la dictadura (Manzano, 2014; De la Maza y Garcés, 1985; Baño, 1985), especialmente en el involucramiento que tuvo el Comando Nacional de Trabajadores y la Coordinadora Nacional Sindical (Araya, 2014; Rojas, 2011), mientras que por contraste, en el retorno a la democracia no parece haber una impugnación explícita a la desigualdad por parte de movimientos populares masivos. Esta ruptura puede describirse en términos de desmovilización popular (Oxhorn, 1994; Hipsher, 1996; De La Maza, 2002).

Este artículo tiene como objetivo fundamental comprender la subordinación de los sectores populares en un contexto de alta desigualdad, en ruptura con un periodo inmediatamente anterior de altos niveles de movilización. Ello se hace desde el análisis de la conciencia de clase presente en la Central Unitaria de Trabajadores, principal organización de la clase trabajadora. 
Al respecto hay diferentes hipótesis en la literatura. Por una parte, hay trabajos que han enfatizado que las reformas neoliberales produjeron un contexto de precariedad y flexibilidad del empleo que dificultó las capacidades de acción sindical (Drake, 2003; Muñoz, 2012; Julián, 2014) de un movimiento que venía de ser duramente reprimido por los militares (Drake, 2003; Álvarez, 2010).

Sin embargo, esta no parece una explicación suficiente. Aunque indudablemente hayan tenido efectos, tanto la represión como el giro neoliberal fueron obstáculos superados durante la dictadura, y se pudo desplegar un ciclo de movilización que tuvo como convocante público a los sindicatos y como epicentro a las poblaciones. En ese sentido, hay trabajos que han argumentado que el giro neoliberal y la represión a los sindicatos contribuyeron a la poblacionalización de la protesta (Álvarez, Pinto y Valdivia, 2008; Rojas, 2011; Moulián, 1997; De la Maza y Garcés, 1985; Iglesias, 2007), mientras que la existencia de redes “subterráneas" de organización territorial (Garcés, 2013) así como menores grados de institucionalización que dificultaron el control por parte de la dictadura (De la Maza y Garcés, 1985), fueron factores clave para que la explosión social en dictadura tuviera a las poblaciones como escenario más que los centros de trabajo. Por otra parte, de ser acertada la explicación de la baja conflictividad sindical como efecto del neoliberalismo -en estos términos-, en la posdictadura el movimiento población pudiera haber resistido en mejores condiciones organizativas, cuestión que de hecho no sucedió (Angelcos y Pérez, 2017; De La Maza, 2002; Paley, 2001).

En la literatura existe una segunda hipótesis para interpretar la baja conflictividad social en la postdictadura: la influencia política sobre las organizaciones. Los trabajos que han propuesto esta interpretación concluyen que, en la Central Unitaria de Trabajadores, principal organización de la clase trabajadora primó una orientación de defensa de la transición a la democracia, para lo cual se desarrolló una política de moderación del movimiento sindical y su capacidad reivindicativa (Zapata, 2004; Frias, 2008; Osorio y Gaudichaud, 2016). En ese sentido Zapata (2004: 148) sostiene que "los gobiernos de la Concertación consiguieron que los sectores populares hicieran suyas las prioridades de la "nueva democracia' y auto-limitaran su capacidad contestataria, para pasar de una lógica de enfrentamiento a una lógica de consenso".

Este planteamiento parece especialmente relevante, considerando que no solo entre 1988 y 1998 el presidente de la CUT fue Manuel Bustos, militante democratacristiano, sino que además, como evidencia Osorio (2015), la concertación fue la fuerza hegemónica en el mundo sindical. 
Tabla 1: Resultados de elecciones CUT por partidos políticos (1988 - 2000).

\begin{tabular}{llllll}
\hline & $\mathbf{1 9 8 8}$ & $\mathbf{1 9 9 1}$ & $\mathbf{1 9 9 6}$ & $\mathbf{1 9 9 8}$ & $\mathbf{2 0 0 0}$ \\
\hline DC & $38,4 \%$ & $43,1 \%$ & $25,8 \%$ & $9,2 \%$ & $47,6 \%$ \\
PS & $24,1 \%$ & $34,9 \%$ & $34,9 \%$ & $46,0 \%$ & $26,4 \%$ \\
PC & $22,2 \%$ & $19,7 \%$ & $28,1 \%$ & $37,1 \%$ & $24,7 \%$ \\
Otros & $15,30 \%$ & $2,30 \%$ & $11,20 \%$ & $7,70 \%$ & $1,30 \%$
\end{tabular}

Fuente: Osorio, 2015.

Analizando las tendencias electorales en Chile, Torcal y Mainwaring (2003) observan que en la posdictadura la clase trabajadora tendió a apoyar a los partidos de la Concertación. Considerando ello, Roberts (2002) ha sugerido que la mejor explicación para comprender la coexistencia en Chile de baja conflictividad social en el altísimo nivel de desigualdad, es que la DC y el PS habían dejado de movilizar políticamente los temas de clase.

Este artículo continúa esta misma línea de investigación para explorar qué factores posibilitan la subordinación de los sectores populares en un contexto de alta desigualdad. En ese sentido esta investigación no se enmarca en los estudios sorbe sindicalismo o movimiento de trabajadores, sino en los estudios de clase. Para tal objetivo estudiar una organización sindical, por representativa que esta fuere, es un ejercicio incompleto, dejando pendiente otras dimensiones en que se expresa la clase trabajadora como son el movimiento poblacional o sus organizaciones políticas.

Sin embargo, estudiar una organización con altos niveles de institucionalización y mecanismos de carácter representativo de un entramado social que constituyen una parte significativa de la clase trabajadora organizada, presenta ventajas metodológicas para comprender los mecanismos de subordinación de clase. La organización política de una clase es un fenómeno cuyo estudio presenta una serie de problemas teóricos y empíricos como la disparidad de criterios para conceptualizar esa relación, la necesidad de demostrarla, y posteriormente discriminar con qué sectores existen lazos.

Por el contrario el caso del movimiento poblacional, donde la pertenencia de clase, si bien ha sido cuestionada, se puede argumentar desde la noción de experiencias de clase (Cury, 2018), presenta el problema de que en este periodo ha sido caracterizado como un archipiélago (De La Maza, 2002), lo que tiene la consecuencia de que establecer conclusiones generales no solo tiene el problema de reconstruir una muestra representativa en términos de fuentes, sino que también implica sistematizar esa fragmentación.

Si bien esos problemas deben enfrentarse para llegar a una interpretación robusta sobre el periodo, es razonable comenzar por el análisis de una organización cuya pertenencia de clase puede demostrarse desde sus propias definiciones, pero que además en el periodo de interés dejó cristalizadas sus posiciones en la 
documentación producida: actas de conferencias, documentos de congresos y el periódico Unión y Trabajo (1990-1996) fueron las fuentes analizadas en esta investigación.

\section{Conciencia de clase}

Dentro de la literatura previamente citada llama la atención la interpretación que presenta Zapata (2004), donde propone que la subordinación de los sectores populares tendría una mezcla de influencia gubernamental y auto-constricción, exclusión o represión. Esta tesis parece estar en sintonía con lo propuesto por Erik Olin Wright (2000: 193-195) en relación a que las formas de conciencia empírica de clase son la variable explicativa de las tendencias a la movilización o desmovilización. En ese sentido, una deficiencia presente en varias de las investigaciones citadas (Zapata, 2004; Frias, 2008; Osorio y Gaudichaud, 2016; Torcal y Mainwaring, 2003; Roberts, 2002) es que no explicitan el esquema conceptual desde el cual es posible -o no- especificar las relaciones entre clase, experiencias de clase, conciencia, acción y partidos.

Por ello, la presente investigación busca no solo aportar nueva evidencia a una línea de investigación ya iniciada, sino que también proponer un esquema teórico para entender de manera más amplia el entrelazamiento entre la clase trabajadora en el neoliberalismo, la Concertación y un tipo específico de conciencia que tiene como consecuencia la subordinación de los sectores populares.

En los estudios de clase se ha usado la noción de conciencia de clase para describir aquellos aspectos subjetivos asociados a la desigualdad. El concepto puede rastrearse hasta los trabajos de Marx (1987; Marx y Engels, 1974), aunque no solo ha sido trabajado dentro del campo de los marxismos (Wright, 1994; Thompson, 2012; Lukács, 1978), sino que también ha sido relevante para algunos de los

principales teóricos de la tradición weberiana (Parkin, 1978; Giddens, 1996; Lockwood, 1958).

Ambas tradiciones tienen un importante nivel de consenso sobre las principales dimensiones para estudiar. En los trabajos de Giddens (1996), Mann (1973) y Katznelson (1986) se encuentran sistematizadas aproximaciones que tienen al menos tres elementos comunes: identidad de clase, intereses materiales, y reflexión sobre la estructura social.

La identidad de clase no ha variado mucho de como fuera propuesta por Thompson (2012), en tanto que es el reconocimiento común de un grupo social diferenciado de otro en función de la posición que ocupan en la estructura social.

Si bien los intereses materiales generalmente están presentes, puede variar mucho la forma en que son conceptualizados. Así, mientras algunos autores se han centrado en la discusión de si los intereses materiales son objetivos o subjetivos 
(Wright, 1993), otros se han enfocado en medir el nivel en que subjetivamente los grupos sociales ven que sus intereses se encuentran en oposición a los de otros grupos (Mann, 1973). Giddens (1996) plantea un aspecto particularmente relevante: que parte de las distintas formas de conciencia contienen diferentes formas de conceptualizar los intereses materiales: pueden ser atribuidos a los individuos, estructurados en clases, armónicos entre clases o conflictivos entre clases.

La reflexión sobre la estructura social es donde menor consenso hay. Mann (1973) y Giddens plantean que la idea -por vaga que sea- de una sociedad alternativa con la cual reemplazar la existente, constituyen una conciencia de tipo revolucionaria. El problema es que esa es una posibilidad -de hecho, la menos frecuente-, y no encajan bien aquellos tipos de conciencia que entienden el orden social como legítimo.

Esto lleva al problema del sistema de valores con el cual las personas juzgan lo que es justo y lo que no, y desarrollan consecuentes orientaciones de acción. Si bien el sistema de valores es recurrente en los trabajos sobre conciencia de clase (Thompson, 2012; Wright, 2000; Katznelson, 1986; Mann, 1973), suele ser mencionado, pero sin ocupar un lugar específico en la arquitectura conceptual.

Al respecto hay una posibilidad de diálogo muy fructífero con aportes teóricos provenientes desde diferentes perspectivas. Sumariamente, hay un importante consenso en los trabajos de Axel Honneth (2011) y Boltanski y Chiapello (2002). En ambos trabajos, la conciencia opera como un marco teórico-moral a partir del cual se juzgan como injustas determinadas experiencias.

Los grupos sociales subalternos suelen no ser capaces de expresar estas experiencias en forma de valores generalizables, sino en forma de reproche moral (Honneth, 2011) asociado a sentimientos de indignación que derivan directamente desde la experiencia. Desde ambas perspectivas los sentimientos de injusticia no devienen por sí mismos en crítica articulada. Para que eso suceda se requiere de apoyo teórico-argumentativo que sea capaz de interpretar las experiencias de injusticia: desarrollando un proceso de reconocimiento, identificación y codificación de aquello que es fuente de indignación, y de los principios de organización social en que se basa (Boltanski y Chiapello, 2002). De esta manera, el marco teórico-moral liga las situaciones de indignación con un sistema de valores y orientaciones de acción, hegemónicas, negociadas o radicales (Parkin, 1978) dependiendo si asuman los principios de los grupos sociales dominantes, en una corrección desde los principios hegemónicos o desde unos principios distintos.

De este modo para analizar la reflexión sobre la estructura social, como una dimensión de la conciencia de clase, se debe observar las críticas y valoraciones del orden social para, a partir de ellas, reconstruir el marco teórico-moral desde el cual se juzgan las experiencias de clase en términos de justicia o injusticia y se plantean orientaciones de acción colectiva. 
Uno de los principales debates en el campo de estudios sobre clase es si los procesos de formación y conciencia de clase se desarrollan de manera espontánea a partir de la experiencia de vivir las estructuras capitalistas (Thompson, 2012; Wright, 2000; Giddens, 1996; Katznelson, 1986) o si, al contrario, estos procesos requieren de una intervención externa para adquirir expresión política (Przeworski, 1988; Parkin, 1978).

Al respecto Mann (1973), Boltanski y Chiapello (2002) y Honneth (2011) convergen en la idea de que existe una interacción entre las experiencias de clase y las ideologías elaboradas que operan como un análisis de estructuras en que se insertan las experiencias vividas, pudiendo legitimarlas, corregirlas o imaginar otras estructuras sociales alternativas.

Siguiendo este supuesto, estudiar la conciencia de clase de la Central Unitaria de Trabajadores requiere, necesariamente, ponerse en relación con los procesos de conversión ideológica y teórica que vivieron los dos principales partidos que dirigen la organización sindical en este periodo: la Democracia Cristiana y el Partido Socialista.

\section{La renovación socialista y democratacristiana}

El golpe de Estado de 1973 fue el catalizador de la conversión ideológica de la mayor parte de los sectores que en 1970 proponían alternativas no capitalistas para el país.

En el caso del PS, en 1979 se divide entre un sector que proclama la renovación, liderado por Carlos Altamirano y otro que la postergará hasta una década más tarde, liderado por Clodomiro Almeyda. Según relata Carlos Altamirano a Gabriel Salazar (2010), la división estuvo marcada por la convergencia de varios temas: alineaciones internacionales, la lectura de la derrota de la Unidad Popular, la política de alianzas que permitiera poner término a la dictadura, y la cuestión del marxismo. Podría resumirse el planteamiento inicial de la renovación en algo así como ruptura con los países socialistas, la interpretación de que la Unidad Popular había fracasado por la debilidad de no conformar un bloque por los cambios con la DC, lo cual señalaba la necesidad de la alianza estratégica con la Democracia Cristiana para retornar a la democracia. La cuestión del marxismo tenía dos problemas: por una parte, Altamirano sostiene que "nosotros cuestionábamos abiertamente la validez del marxismo-leninismo para interpretar la nueva realidad histórica que estábamos viviendo" (Salazar, 2010: 194), y por otra, la alianza con la Democracia Cristiana implicaba descartar el marxismo.

Así, podría condensarse la transformación ideológica del socialismo en tres elementos: el abandono del marxismo, la orientación a la democracia como proyecto político, y la renuncia a la transformación del capitalismo. 
Primero, como señala Alvear (2013) el marxismo proveía una arquitectura conceptual para interpretar la realidad social en términos de oposiciones de clases además de una meta política a alcanzar. Conceptualizar la sociedad en términos de antagonismos fundamentales implicaba una concepción en la cual los intereses de clases se conciben como irreconciliables con las formas políticas e ideológicas de las clases dominantes. En ese sentido, aparece la meta política de sustituir el orden social capitalista, definido como ilegítimo e inhumano, y construir "sobre sus ruinas una sociedad socialista” (Almeyda, 1986: 185).

Alvear (2013: 64) plantea que el abandono del marxismo debilita progresivamente el abordaje de la problemática de la injusticas en el ámbito de la distribución de las riquezas y el trabajo, que a fines de la década de los ochenta sería conceptualizada con referencia a la "equidad", en el lenguaje de los gobiernos concertacionistas y que la CEPAL (1992) elaborará como la orientación hacia el crecimiento con equidad.

El segundo punto es la relación de socialismo y democracia. Moulián (1997) señala que esta problemática fue el puntapié inicial de la renovación. Alvear (2013: 75) plantea que de hecho la idea de democracia reemplazó como meta política a la idea de socialismo, de manera que se puso "el problema del régimen político por sobre el problema del modo de producción". Esto reforzaba el abandono de la concepción política vinculada al marxismo, en la medida en que había aspectos que no terminaban de estar alineados con el objetivo democrático, como era el pensamiento leninista que argumentaba la idea de dictadura del proletariado y podía justificar un régimen despótico. Moulián (1993) plantea que la necesidad imperiosa de desembarazarse del leninismo era dotarse de armas ideológicas contra la dictadura militar que enfrentaban en Chile.

Baño (1985) señala que este conjunto, acaba por vaciar de contenido propio la idea de socialismo, y la reduce a la posibilidad de existencia de un régimen democrático.

Una de las consecuencias de esta transformación de meta política y arquitectura conceptual, es la transformación de las formas de acción política. Si el socialismo antes de la renovación se basaba en la lucha de clases, en función de lo cual ponía a los sectores populares y la clase obrera como agentes privilegiados de la posibilidad de la transformación social; luego la renovación plantea la interpretación de que una de las causas del golpe de Estado fue la falta de articulación con el centro político, que los cambios no pueden ser impuestos por una minoría, sino que deben sostenerse con mayorías institucionales (Salazar, 2010; Valenzuela, 2014). Ello es lo que fundamenta inicialmente la búsqueda de alianza con la Democracia Cristiana. Pero tiene implícito un cambio en la lógica política, donde se abandona la conflictividad y la movilización social, y se reemplaza por la construcción de consensos, y negociación a nivel de élites al interior de las instituciones. En ese 
contexto, se abandona el discurso popular del PS, y pasa a hablarse de un partido amplio, abierto a toda la sociedad, incluyendo las clases propietarias. El actor privilegiado por el PS ahora será sencillamente "la ciudadanía” (Valenzuela, 2014; Alvear, 2013).

Nótese que en la categoría de ciudadanía no existe una contradicción fundamental de intereses, lo cual implica una redefinición en la cual lo político en general, y el PS en particular, dejan de ser representantes del conflicto de intereses materiales entre clases (Alvear, 2013).

El corolario de la renovación socialista fue el abandono de las críticas sustanciales al capitalismo (Moulián, 1997), más allá todavía, no acepta la existencia de este modo de producción solo en términos instrumentales sino que en buena medida se incorpora a su propio ideario (Alvear, 2013), y lo hace en su versión neoliberal: "se asume la economía de mercado, hay duda con la intervención estatal, se prefiere optar por políticas que mejoran la capacidad emprendedora de las personas por sobre un Estado activo" (Valenzuela, 2014: 193).

En el caso de la Democracia Cristiana ha sido menos estudiada su transformación ideológica. En los años sesenta, respecto de la estructura social la DC proponía la "sustitución del régimen capitalista por un nuevo orden en el cual los trabajadores tengan la propiedad del capital y el goce de los beneficios de la producción; transformación, en consecuencia, del sistema capitalista en un sistema comunitario" (Instituto de Estudios Políticos del PDC, 1962: 20).

Moulián (1997) sostiene que este partido estuvo atravesado por las disputas entre una corriente socialcristiana que va a continuar propugnando por el comunitarismo, y una corriente que va progresivamente liberalizándose. En los ochenta, la posición oficial del partido ya no cuestiona el orden capitalista en general, pero si la mercantilización extrema del neoliberalismo. En ese sentido se puede leer la producción de CIEPLAN, centro de investigación de la DC. Por ejemplo, Alejandro Foxley (1985) sostenía que el neoliberalismo no constituía una opción de desarrollo y crecimiento, dado su carácter excluyente, y debía ser reemplazado por un nuevo contrato social que reconstruyera una comunidad. En Chile Actual (1997), Moulián contrasta esas posiciones con el recuerdo de que pocos años más tarde, cuando el mismo Foxley fue ministro de hacienda de Aylwin, Andrés Allamand expresó que hubiera sido un excelente ministro de Pinochet, en referencia a la continuidad en la política económica que pocos años antes criticaba.

Al igual que en el caso del PS no se trata de una adaptación pragmática, sino la interiorización del neoliberalismo a la ideología propia. En la década del dos mil en un documento de síntesis del pensamiento partidario se sostenía que:

El mercado es el principal instrumento de asignación de los recursos.

Debe ser lo más competitivo y transparente que sea posible. Se valora 
en general la conveniencia de mercados abiertos e integrados (...) Valora en especial su capacidad demostrada para crear riqueza, favorecer el ascenso social e incentivar la innovación tecnológica y el avance científico (ICHEH, 2003: 63).

De esta cita se puede inferir una justificación de que el capitalismo es un sistema económico no solo beneficioso para los propietarios, sino para el conjunto de la sociedad. Además, se expresa una concepción de que los intereses en la sociedad son convergentes: no existen intereses distintos ni conflictivos entre clases.

En el próximo apartado se examinará en detalle la conciencia de clase presente en una CUT dirigida por militantes socialistas y democratacristianos, y que, por lo tanto, fueron partícipes de estos procesos de conversión ideológica, y la influencia es notable.

\section{La conciencia de clase en la Central Unitaria de Trabajadores}

\subsection{Identidad de clase}

El carácter sindical de la organización, así como el nombre escogido marcan una cierta identidad de clase trabajadora, pero no es evidente cuál es el contenido de esa identidad. Sistematizando diferentes documentos, es posible destacar tres elementos.

En primer lugar, la clase trabajadora se define como aquella que vive de su propio trabajo: “(...) agrupa en su seno a todos los trabajadores manuales e intelectuales, sea que realicen su trabajo en forma dependiente o independiente siempre que en este último caso vivan de su propio trabajo-"2 (Central Unitaria de Trabajadores, 1990). Esto es relevante, puesto que derriba distinciones que tradicionalmente la literatura ha puesto de relieve para distinguir a la clase trabajadora de la clase media, como son la frontera entre trabajo manual y no manual, y entre asalariados e independientes y entre el sector industrial y manufacturero, el cual ni siquiera es mencionado (Braverman, 1981; Poulantzas, 2005; Goldthorpe y Erikson, 1992).

Luego, esta posición en la estructura social es descrita como un lugar que tiene cierta homogeneidad en sus condiciones de vida: los trabajadores corresponden a "los sectores de menores ingresos"3 o una situación abiertamente de pobreza.

Tercero, además de homogeneidad en las condiciones de vida, se identifica que las personas que viven de su propio trabajo en Chile tienen una cierta

2 Central Unitaria de Trabajadores, 1990. Primer Congreso Nacional Ordinario. Unidad para profundizar la democracia, Punta de Tralca: CUT.

3 CUT, 1991. Tareas futuras de los trabajadores. Unión y Trabajo, Diciembre. 
experiencia de clase compartida que es descrita como "la sufrida clase trabajadora chilena"4.

Es relevante destacar que, además, para la CUT la identidad de la clase trabajadora se distingue de otra clase: los empresarios. Las referencias encontradas entienden que esta posición en la estructura social comparte unas condiciones de vida que los sitúan como "grupos y sectores privilegiados" ${ }_{5}$, los que son beneficiados por el modelo económico6.

Sobre esto hay un elemento interesante. Si los trabajadores son definidos como quienes viven de su propio trabajo, la oposición lógica es que no son trabajadores quienes viven del trabajo ajeno, o lo que es lo mismo, viven de la explotación del trabajo. Sin embargo, no se encontró ninguna evidencia que describiera explícitamente en esos términos a la posición de los propietarios, por lo que es un elemento latente, que va describiendo un tipo de conciencia de clase que evade el conflicto entre clases.

\subsection{Intereses materiales}

De acuerdo a lo señalado por Giddens (1996) la primera pregunta es cuál es la unidad de la realidad social que es portadora de intereses materiales: los individuos o colectividades. Al respecto, se puede observar que la conciencia de clase presente en la CUT entiende que los intereses materiales son de orden colectivo y que se encuentran ordenados por las posiciones en la estructura social. Así, los trabajadores presentan unos intereses comunes y diferentes de los propietarios. La misión de la Central establece que ella "representará los intereses generales de los trabajadores", , lo cual es reafirmado en diversas ocasiones en que se define "la representación de los intereses de los trabajadores, haciendo sentir su voz, luchando por sus reivindicaciones",, o "asegurar la autonomía de nuestras organizaciones y elevar la eficacia de su acción en defensa de nuestros intereses comunes"9.

En el otro polo de la estructura social también se puede identificar la existencia de intereses colectivos: "los intereses de las castas privilegiadas"10 o "intereses de las transnacionales y de los grandes empresarios"11 los cuales aparecen representados por la dictadura militar y los partidos que la apoyaron.

\footnotetext{
4 CUT, 1990. Nuestro interés por las reformas laborales. Unión y trabajo, Septiembre, p. 1.

5 CUT, 1990. La tarea continúa. Unión y trabajo, Agosto, p. 1.

6 CUT, 1993. Una modernización social. Unión y Trabajo, Julio.

7 Central Unitaria de Trabajadores, 1990. Primer Congreso Nacional Ordinario. Unidad para profundizar la democracia., Punta de Tralca: CUT

8 CUT, 1992. 25 de febrero, día de los mártires sociales. Unión y Trabajo, Febrero.

9 CUT, 1992. Legalización de nuestra central. Unión y Trabajo, Abril.

10 Central Unitaria de Trabajadores, 1992d. Proposiciones Comisión n¹. s.l., s.n.

11 CUT, 1992. Democracia como participación. Unión y Trabajo, Julio.
} 
En este primer nivel de análisis hay un elemento imprevisto. La conciencia de clase de la CUT plantea la existencia de intereses nacionales, entendiendo que su acción colectiva debe "compatibilizar la defensa de nuestros intereses particulares con el interés general del país"12. Esto implica que son intereses que trascienden a las clases y son compartidos entre capital y trabajo.

En segundo lugar, se analiza específicamente cuáles son los intereses de cada categoría. Respecto de los intereses de la clase trabajadora, la multisindical establece como horizonte "alcanzar el reconocimiento pleno -político, social y laboral-, en igualdad de derechos, condiciones y posibilidades para su íntegra realización e incorporación al mundo laboral, al fruto mismo, por sueldos dignos y justos"13, lo que significa concretamente preocuparse "del mejoramiento económico, social y cultural de ellos, de sus familias y del pueblo en general, a través de su participación protagónica en los distintos ámbitos de la actividad social"14.

Esta definición contiene fundamentalmente dos elementos: el bienestar material de los trabajadores y la participación política. Ambos aparecen en oposición a la experiencia de clase caracterizada por la pobreza y la exclusión política en que se encuentran los trabajadores, y la estrategia para realizar esos intereses en este contexto es el mejoramiento mediante la corrección de la estructura social existente, incorporando políticas redistributivas.

Un tercio de los chilenos sigue viviendo en situaciones de pobreza y ellos no pueden seguir esperando. Se requiere desde ya una política redistributiva que corrija las tremendas diferencias y desigualdades que subsisten en el país, pese a los éxitos macroeconómicos conseguidos con el esfuerzo de todos, especialmente con el aporte de los trabajadores 15 .

Tenemos que ser capaces de sacar adelante las justas aspiraciones de los trabajadores y terminar pronto con la situación de pobreza que afecta a un tercio de chilenos y lograr una justa distribución de la riqueza 16 .

Nótese además que la organización de trabajadores pide permiso para plantear la crítica correctiva al modelo económico en función de sus intereses de clase. Allí se evidencia que existe una subordinación voluntaria de la clase trabajadora. Esta posición será especialmente notable entre 1990 y 1992, en que se

\footnotetext{
12 CUT, 1994. Ante los cambios que vienen. Unión y Trabajo, Enero-Febrero.

13 Central Unitaria de Trabajadores, 1992. Anexo 2. Coincidencias generales. s.l., s.n.

14 Central Unitaria de Trabajadores, 1990. Primer Congreso Nacional Ordinario. Unidad para profundizar la democracia., Punta de Tralca: CUT.

15 CUT, 1994. Los silencios del ministro de hacienda. Unión y Trabajo, Septiembre.

16 CUT, 1996. Editorial. Unión y Trabajo, Abril.
} 
desarrollan los acuerdos marco y la política de concertación social convocando diálogos entre los gremios empresariales, la CUT y el ministerio del trabajo.

Sin embargo, la experiencia de la Central es que esa política de diálogos entre Estado, capital y trabajo favoreció sistemáticamente a los empresarios, y la participación de los trabajadores fue meramente simbólica. En función de ello, hay un declive de esta conciencia ambigua, que "pide permiso" y se va delineando una crítica más explícita a lo injusta de la distribución de la riqueza en el modelo económico neoliberal, dándole relativamente menos importancia a su capacidad de producir riqueza. En consecuencia, va surgiendo más nítidamente el objetivo de un modelo redistributivo: "ya no queremos, ni tampoco aceptaremos, que estas se sigan postergando con la excusa de que los cambios solo son posibles en la medida que lo permita el modelo económico, que ha beneficiado principalmente a los empresarios"17.

Con respecto a la dimensión política en los materiales analizados la conciencia de la CUT enlaza participación y democracia. Se argumenta que esta última constituye un interés de clase para los trabajadores $\mathrm{y}$, por lo tanto, que el movimiento sindical debe luchar por ella. La visión de la central es que la democracia instaura un campo de igualdad entre las personas que pone límites a la concentración del poder en la esfera de económica y que las instituciones democráticas debieran ser un contrapeso al poder empresarial. De esta manera se entiende a la democracia como el régimen político idóneo para que los trabajadores puedan realizar sus intereses de clase. En sus palabras:

Nuestro objetivo principal $\ldots$ es la consolidación y profundización del sistema democrático, que es el único que nos permite luchar con eficacia por nuestras legítimas reivindicaciones 18 .

(...) debe tenerse presente nuestra férrea voluntad de defender esta Democracia que avanza y el desarrollo con participación y justicia, para que nunca más grupos y sectores privilegiados abusen y exploten sin contrapeso a los chilenos indefensos ante la ley y el poder del dinero de los egoístas y antisociales ${ }^{19}$.

Luego de determinar que en la conciencia de la CUT existía la visión de unos intereses comunes a los trabajadores, de acuerdo a las discusiones teóricas, cabe la pregunta de si esos intereses son diferentes a los que portan los propietarios. En ese sentido, en los materiales analizados son relativamente pocas las referencias explícitas que den cuenta de cuáles serían, para la CUT, los intereses específicos de

17 CUT, 1993. Una modernización social. Unión y Trabajo, Julio.

18 CUT, 1990. Crecimiento de un 40 por ciento en 2 años. Unión y Trabajo, Agosto, p. 4.

19 CUT, 1990. La tarea continúa. Unión y trabajo, Agosto, p. 1. 
los empresarios. Esto profundiza la interpretación presentada en la dimensión identidad de clase, con respecto al tipo de conciencia que evade nombrar y abordar el antagonismo entre capital y trabajo.

Por otra parte, esta situación de escasa evidencia implica que para discriminar cuáles percibe la central que serían los intereses materiales de los propietarios, éstos deben inferirse de manera indirecta a través de la acción colectiva de los gremios empresariales.

Entre las formas de acción de clase de los propietarios que identifica la Central se puede destacar la persecución y represión sindical: "En la mayoría de los casos los empresarios mantienen una conducta de abuso y atropello a nuestros derechos, persecución a nuestras organizaciones. La concertación sindicalempresarial que el país requiere sigue esperando una contribución más decisiva del empresariado"20.

Una segunda forma de acción tiene que ver con la defensa pública de una institucionalidad laboral ampliamente beneficiosa para los propietarios, realizando "una campaña propagandística de algunas organizaciones de empresarios y sectores políticos en contra de las reformas" 21 . Sin embargo, la multisindical evidencia que no se trata de una mera defensa de la legalidad, puesto que "(...) incluso esta mala legislación es violada en los hechos por muchos malos empresarios, sin que el gobierno ejecute un masivo y riguroso plan de fiscalización"2 2.

También se menciona el pago de bajos salarios como una acción deliberada, "pensamos que ningún empleador, empresario o patrón debería pagar a sus trabajadores menos de lo que él sabe que no alcanza para sobrevivir"2 3.

En esto caben algunos puntos de la mirada conjunta que tiene la CUT sobre la acción empresarial, que se describe como un "poder patronal y empresarial frecuentemente intransigente" 24 , donde "existen sectores -sobre todo entre el empresariado- que se niegan a aceptar condiciones de igualdad que permitan encontrar soluciones negociadas y consensuadas"25.

Aquí caben dos observaciones más. La primera es que llama la atención la búsqueda de diálogo por parte del movimiento sindical frente a la experiencia de un empresariado intransigente y que no está dispuesto a ello. La segunda es que, aunque no es definido explícitamente en estos términos, parece razonable interpretar que la idea latente en la conciencia de la CUT es que el interés material que le da sentido a la acción colectiva de los propietarios es la maximización de la

\footnotetext{
20 CUT, 1992. Un balance necesario a 1992. Unión y Trabajo, Diciembre.

21 CUT, 1990. La tarea continúa. Unión y trabajo, Agosto, p. 1.

22 CUT, 1992. Diálogo y movilización por nuestros intereses. Unión y Trabajo, Septiembre.

2 CUT, 1991. Informe Rettig. Unión y Trabajo, Marzo.

24 CUT, 1991. Desarrollo institucional. Unión y Trabajo, Agosto.

25 CUT, 1993. Con el pasado se construye el presente y el futuro. Unión y Trabajo, Abril.
} 
ganancia. En ambas observaciones puede notarse que la conciencia de clase presente en la CUT se encuentra tensionada, evadiendo una relación conflictiva que en la práctica experimentan de manera sistemática.

Como se mencionó previamente, resulta imprevisto encontrar una tercera categoría de intereses materiales no fundados en las clases: intereses nacionales. En relación a ellos la organización sindical define "la necesidad de que todos los chilenos asumamos un compromiso de velar por los intereses generales del país, especialmente en términos de consolidar la democracia y de mantener un crecimiento económico sostenido, con justicia y equidad"2 6 .

El crecimiento económico aparece como resultado de la cooperación entre capital y trabajo, de tal manera que ambas partes se ven beneficiadas y pueden mejorar su bienestar material. Nótese que la organización no se limita a identificar analíticamente que la creación de riqueza se produce por la cooperación de dos partes, sino que hay una valoración y un reconocimiento moral tanto al "(...) aporte del sector privado al crecimiento económico"27 como el que realizan los propios trabajadores, aun cuando no hay referencias que detallen en qué consistiría específicamente tal aporte.

Con respecto a la democracia es llamativo que se le define al mismo tiempo como un interés de la clase trabajadora y como un interés nacional. Si en el primer caso se argumentaba que es el sistema que mejor permite la lucha de los trabajadores, en este nivel se plantea que es un fin y un valor en sí mismo, no reductible y no instrumental. Es una forma institucional basada en la igualdad de derechos y valor de las personas: "La democracia, entendemos, es una forma de vida y relación entre hombres y mujeres, definida por el valor de la libertad y de los límites a los grupos que concentran el poder. Sin duda, no es solo un método de elección, sino el ejercicio pleno de los derechos de todos"28.

$\mathrm{Si}$ bien no se utiliza la palabra igualdad para describir las instituciones democráticas, la idea del ejercicio pleno de los derechos de todos permite interpretar en esa dirección la concepción de la CUT, en el sentido de que "la participación democrática implica la manifestación de todos los sectores. Es así, que en el libre espacio que otorga la democracia, surgen cuestionamientos, demandas que deben encontrar los canales de expresión necesarios”29. De esta manera el imaginario que existe sobre la democracia es que las desigualdades surgidas en el ámbito del mercado no se proyectan hacia las instituciones que canalizan en igualdad de condiciones las demandas de los grupos sociales.

Esto es de tal importancia para la multisindical que expresa la subordinación

\footnotetext{
26 CUT, 1994. Ante los cambios que vienen. Unión y Trabajo, Enero-Febrero.

27 CUT, 1994. El rol de las empresas públicas. Unión y Trabajo, Noviembre.

28 CUT, 1992. Democracia como participación. Unión y Trabajo, Julio.

29 CUT, 1992. Democracia como participación. Unión y Trabajo, Julio.
} 
del bienestar material de los trabajadores: "La CUT ya hizo su aporte a la transición democrática al aceptar la forma gradual en que se está tratando de dar respuesta a los problemas de los trabajadores"30.

Aquí hay dos fisuras discursivas que destacar. Primero, esta concepción implica que para la Central los intereses de los propietarios no solo son legítimos de ser expresados y realizados, sino que se asume que ello es beneficioso no solo para el capital, sino para el conjunto del país, por ello es un interés nacional.

Y lo es porque, como se evidenciará en los siguientes apartados, la organización defiende la tesis de que una economía basada en la empresa privada ha tenido una gran capacidad de creación de riqueza que beneficia a toda la comunidad. En ese sentido la democracia expresa un mecanismo de mediación consensual entre los intereses de capital y trabajo, lo cual maximiza el bienestar material de ambos. Ello se plantea en oposición a la experiencia de la dictadura, donde los intereses del capital se impusieron en el Estado mediante la violencia. En ese sentido, no cabe interpretar la conciencia de la Central como una conciencia hegemónica, en tanto que no asume que el interés de la clase dominante como un interés nacional, sino que el interés nacional es que la dominación de clase no recurra a la violencia, sino que se exprese por mecanismos consensuales. Es, por ello, una conciencia subordinada.

Esto abre la segunda fisura. Si la democracia es un interés nacional implica que es un interés compartido por los capitalistas. El problema es que si la democracia es definida como un sistema que pone límites a los sectores privilegiados - de tal modo que los grupos subordinados puedan participar de la igualdad de derechos-, no es evidente por qué una democracia participativa sería un interés concreto para las élites. En las fuentes consultadas para esta investigación no se encontró ninguna respuesta a esta cuestión, sin perjuicio de que ella pudiese encontrarse en otras fuentes.

Luego de haber constatado que en la conciencia de la organización sindical existían tanto intereses nacionales como intereses de clase, la pregunta teórica que sigue es cómo se entendía la relación entre los intereses materiales de capital y trabajo. Al respecto se plantea que en la conciencia de la Central coexisten relaciones de contradicción y de convergencia.

En principio el problema de la distribución de la riqueza es una dimensión en que hay contradicción de intereses, pero recuérdese que la tesis de la CUT es que los intereses económicos de los trabajadores se realizan en la medida en que hay instancias de participación democrática, y ellas consisten en contrapesos a los grupos de poder. En ese sentido a nivel político también hay -en cierta formacontradicción de intereses.

з 0 CUT, 1992. Constituidas las comisiones tripartitas. Unión y Trabajo, Junio, p. 15. 
Sin embargo, parte de la concepción de democracia que plantea la organización va en la línea de la institucionalización de intereses contrapuestos entre grupos sociales, y abordar esas diferencias por medio de la negociación y la búsqueda de consensos, sin recurrir a la confrontación. De ahí puede deducirse la noción de que, si bien el carácter interrelacionado de las posiciones de riqueza y pobreza impone cierta estructura de contraposición de intereses, no está dado que ellos sean antagónicos, sino que es posible la convergencia. Si la relación entre los intereses es de contradicción o convergencia es una cuestión contingente donde interviene también la voluntad de los propietarios: "Pero pedimos a los empresarios que hagan un esfuerzo mayor al que han hecho hasta ahora" 31.

Los intereses nacionales, la democracia y el crecimiento económico aparecen como instancias que no solo son resultado de la cooperación entre trabajadores y capitalistas, sino que son contextos que facilitan la convergencia entre clases maximizando el beneficio mutuo de bienestar material, aún dentro del marco desigual del neoliberalismo. De manera más general puede inferirse que lo que la conciencia de la multisindical propone como su horizonte de justicia consiste en corregir las desigualdades existentes mediante complementos a las relaciones capitalistas existentes de modo tal que haya equilibrios entre clases, y no su transformación o reemplazo por otra estructura que supere la existencia de las desigualdades de clase, como propusiera en su declaración de principios la antigua Central Única de Trabajadores, fundada en 1953 (Gaudichaud, 2005: 83).

Hay evidencia que permite sostener razonablemente que esta concepción de justicia es producto de la influencia democratacristiana, militancia predominante en la dirección de la organización hasta 1996.

La llamada "Doctrina Social de la Iglesia" (...) proclama la dignidad del Hombre, de todo hombre, establece los deberes generales del Estado en torno al bien común, el respeto a la dignidad de los obreros, el principio de salario justo como una relación entre lo convenido y lo necesario, la relación entre propiedad privada y el bien común, el derecho de asociación de todo ciudadano y, en general plantea la sociedad como un todo armónico con equilibrios de las clases sociales, afirmando que los deberes de justicia son imperativos en la sociedad humana. Deberes de obreros y patrones ${ }^{2}$.

Nótese que allí se plantea el horizonte normativo de una sociedad armónica, la cual consiste en desigualdades dentro de cierto margen de equilibrio que permita condiciones de vida dignas a la fuerza de trabajo. Esta idea de

31 CUT, 1994. Lo que viene. Unión y Trabajo, Diciembre.

32 CUT, 1991. Día internacional del trabajo. Unión y trabajo, Abril. 
equilibrio supone un tipo de relación de reconocimiento mutuo entre propietarios y trabajadores que fundamenta la cooperación y la construcción de consensos, en oposición a una relación de confrontación. Es especialmente relevante que esta sea la orientación de valor del movimiento sindical, puesto que, como se verá más adelante, la experiencia de clase de los trabajadores en el neoliberalismo no solo se distancia de esta concepción, sino que ella pone en duda las premisas sobre las cuales descansa la posibilidad del consenso entre capital y trabajo.

\subsection{Reflexión sobre la estructura social}

El referente empírico para analizar esta dimensión de la conciencia de clase es el juicio que existe sobre el modelo neoliberal, desde la clave de lectura que proponía Honneth (2011): que los grupos subordinados expresan sus concepciones morales propias en forma de criterios de reproche, antes que como valores generalizables argumentados.

La organización sindical caracteriza al neoliberalismo por aspectos comúnmente mencionados en la literatura (Garretón, 2012; Ffrench-Davis, 2003): predominio del sector privado, apertura económica exterior, primacía de los mecanismos de mercado y relaciones laborales desequilibradas en favor del empresariado: "(...) el sector privado se constituye en el pilar absoluto de la modernidad y desarrollo" 3 ; “(...) intentan demostrar que los salarios de los trabajadores están bien y, por lo tanto, no es necesaria ninguna reforma de las leyes laborales, por cuanto el "mercado" resolvería las cosas"34.

Este modelo tiene una misma consecuencia en múltiples dimensiones de la vida social, la producción de desigualdad:

Cotidianamente verificamos las diferencias que existen en la calidad de la educación, en las prestaciones de servicios de salud, en el tipo de vivienda que se construyen, en la seguridad social que se recibe y en general en la desigual distribución de la riqueza que el país produce ${ }^{35}$.

El mejoramiento de los sueldos ha beneficiado fundamentalmente a los gerentes y ejecutivos de alto nivel36.

Además de la desigualdad en la distribución de la riqueza y las condiciones de vida, en los documentos de la CUT se puede identificar la crítica al neoliberalismo respecto de la distribución del poder económico que produce:

з 3 CUT, 1994. El rol de las empresas públicas. Unión y Trabajo, Noviembre.

34 CUT, 1995. Mentiras y embestida empresarial. Unión y Trabajo, Marzo.

35 CUT, 1993. Una modernización social. Unión y Trabajo, Julio.

36 Central Unitaria de Trabajadores, 1992a. Anexo 2. Coincidencias generales.. s.l., s.n. 
"Rechazo de la CUT al control del sistema previsional por parte del sector empresarial y, en particular, de los grupos económicos y las transnacionales"37; "una tendencia neoliberal que margina a las organizaciones de los trabajadores y presenta nuestros legítimos derechos como un obstáculo para el desarrollo económico"38.

También se observa evidencia de críticas del movimiento sindical a los fundamentos del modelo económico, en relación al mercado como principal forma de asignación de los recursos y de distribución del bienestar en la sociedad. Así ya se advertía en la crítica a la fijación de los salarios por mecanismos de oferta y demanda, pero más en general plantean que: "Seguir pensando que el sector privado es capaz de resolver los problemas de mala distribución es un error. (...) los grandes problemas que afectan a la sociedad no han encontrado solución en base al libre mercado dirigido por el sector privado" 39.

Sin embargo, son escasas las propuestas en otra dirección que se pueden encontrar en los documentos. En términos generales se propone "impulsar una estrategia de desarrollo económico que esté al servicio de las grandes mayorías"40, y hay innumerables referencias en la línea de "un sostenido crecimiento económico con justicia y equidad" 41 . Nótese que este proyecto de sociedad es precisamente el elaborado por los intelectuales concertacionistas (CEPAL, 1992; Garretón, 2012; Ffrench-Davis, 2003)

Sin embargo, el horizonte de crecimiento con equidad no es desarrollado por la CUT más que en dos aspectos: la necesidad de políticas redistributivas y unas relaciones laborales equitativas entre trabajadores y empleadores.

Sobre ello, a partir de la oposición lógica de los elementos de definición y crítica del neoliberalismo, podría proponerse una hipótesis estructural de la estructura social alternativa que podría haber estado latente en la conciencia de la multisindical: no predominio del sector privado, presencia de medidas proteccionistas, el uso de mecanismos de asignación de recursos distintos del mercado, y una participación deliberativa de los trabajadores. Todos son elementos dentro del marco de las relaciones capitalistas, y buscan una mejora en las condiciones de negociación entre capital y trabajo.

En ese sentido, llama la atención que casi la totalidad de las críticas sobre la estructura social refieren al concepto de neoliberalismo, y casi no existen referencias sobre el sistema capitalista más en general. La única referencia explícita encontrada plantea que "el capitalismo busca incrementar la producción reduciendo

37 CUT, 1991. II Conferencia nacional. Unión y Trabajo, Mayo.

38 CUT, 1994. Otro año construyendo futuro. Unión y Trabajo, Agosto.

з 9 CUT, 1994. El rol de las empresas públicas. Unión y Trabajo, Noviembre.

40 CUT, 1991. II Conferencia nacional. Unión y Trabajo, Mayo.

41 CUT, 1990. Las proyecciones y metas se superaron. Unión y Trabajo, Agosto, pp. 2-3. 
la cantidad de trabajadores empleados. Esto no sería grave si el gobierno y los empresarios, simultáneamente, crearan nuevos puestos de trabajo"42. En ella se puede observar dos cosas.

Primero, que no hay una comprensión de la estructura que produce desigualdad en función de las relaciones sociales. No parece que la reducción de los trabajadores empleados sea una definición del sistema capitalista. Puede que efectivamente sea una consecuencia de la aplicación de lógicas capitalistas al interior de las unidades productivas, pero no describe ni las relaciones sociales que lo constituyen, como ha hecho el marxismo para definir el capitalismo; como tampoco describe aquellas lógicas de acción económica típicas del capitalismo, como por ejemplo ha planteado la tradición weberiana.

Segundo, en términos políticos, esta interpretación de crítica por las externalidades negativas que existen, no solo podrían hipotéticamente ser corregidas al interior de relaciones capitalistas (en este caso, si los mismos propietarios o el gobierno crearan nuevos puestos de trabajo); sino que, de hecho, la problemática del empleo, generación y pérdida de puestos de trabajo, es uno de los temas más recurrentemente abordados en los discursos hegemónicos, por ejemplo en la idea de "la creación de empleo".

Por último, es preciso señalar que también hay formas de justificación del neoliberalismo que van a ser particularmente relevantes entre 1990 y 1992. Éstas se encuentran como matiz a las críticas antes señaladas, oponiéndoles los logros del modelo en términos económicos.

Aunque reconocemos la necesidad de medidas antiinflacionarias y valoramos la estabilidad de las variables macroeconómicas, no podemos aceptar que nuevamente el control futuro de la inflación sea realizado a través de la pérdida del poder adquisitivo de los trabajadores 4.

El país exhibe logros macroeconómicos que son indiscutibles y que es preciso valorar, pero que no son suficientes para resolver la dramática situación de pobreza que afecta a un tercio de los chilenos44.

\section{Conclusiones}

A lo largo del desarrollo de este artículo ya es posible apreciar varios elementos que permiten comprender la subordinación de los sectores populares en el contexto de alta desigualdad que caracterizó el periodo de postdictadura.

42 Central Unitaria de Trabajadores, 1992. Anexo 2. Coincidencias generales. s.l., s.n.

43 CUT, 1990. Ya hemos sido sometidos a sacrificios que son excesivos. Unión y Trabajo, Octubre, p. 12.

${ }_{44}$ CUT, 1992. Un balance necesario a 1992. Unión y Trabajo, Diciembre. 
Sumariamente, en la principal organización de la clase trabajadora existía una conciencia marcada por una identidad de clase trabajadora que, si bien se atribuye a una posición en la estructura social que tiene unas condiciones de vida homogéneas, y diferentes de otro grupo social que no vive de su propio trabajo, se evade el nombrar esa relación en términos que pudieran explicitar un conflicto latente. Con respecto a los intereses materiales, estos no son taxativamente diferentes y opuestos entre capital y trabajo, como señalaba Thompson (2012). Por el contrario, hay intereses nacionales que son comunes a explotadores y explotados, y se insiste contra la experiencia- en la posibilidad de convergencia de los intereses de trabajadores y capitalistas. Junto con ello hay un juicio ambiguo de la estructura neoliberal, donde convive la crítica correctiva con la justificación. Se propone denominar este tipo de conciencia de clase como una conciencia hipoconflictiva.

Desde esta forma de conciencia se comprende la apuesta por formas de acción de clase mediante la argumentación racional hacia los gremios empresariales y el gobierno, y la canalización institucional de demandas bajo la nueva administración civil del Estado.

Pero esa no es, todavía, la explicación completa. Especialmente en la reflexión sobre la estructura social se observan exigencias de justicia cuya elaboración teórico-moral es fragmentaria. No es que no exista un apoyo teórico argumentativo que reconozca, identifique y codifique las experiencias de injusticia (Boltanski y Chiapello, 2002) vividas en el marco de relaciones de clase, sino que el apoyo teórico-argumentativo que está presente busca deliberadamente la convergencia entre capital y trabajo.

Como se argumentó previamente, de acuerdo a la propuesta de Honneth (2011) las experiencias de injusticia interactúan con las ideologías elaboradas que intervienen sobre la clase trabajadora, por lo que se debe hacer el ejercicio de conectar los procesos de transformación ideológica en los partidos que presidieron la organización sindical. Al respecto la renovación socialista reemplaza la arquitectura conceptual que entendía los procesos sociales y políticos en términos conflictivos, por una concepción que ya no tiene como tema principal a la estructura social, sino el régimen político, y que no solo abandona la idea de reemplazar el capitalismo por otra estructura social, sino que valora positivamente el neoliberalismo, aunque le plantea correcciones parciales.

En el caso de la Democracia Cristiana, hay una postura histórica de rechazo a las interpretaciones de lo social basadas en antagonismos de clase. Pero esa negativa en los años sesenta se expresó en un proyecto de sustitución del capitalismo por otra estructura social que resolviera las problemáticas de la clase trabajadora mediante formas de propiedad colectiva de los medios de producción, la cual es abandonada por el partido $y$, al igual que en el PS, se interioriza el capitalismo neoliberal en el propio ideario democratacristiano. 
Así, puede entenderse la renuencia de la Central Unitaria de Trabajadores dirigida por la Democracia Cristiana a la conflictividad social, y que, por el contrario, insista en la posibilidad de convergencia de los intereses entre propietarios y trabajadores, aún en contra de la experiencia sistemática que la misma organización describe.

En el caso de la evaluación del modelo neoliberal también puede rastrearse la influencia ideológica de los partidos en la medida en que está presente exactamente la misma justificación en la reflexión de los partidos y la CUT: la eficiencia y su capacidad de producir riquezas. También es compartida la crítica a los efectos en desigualdad y la referencia a una posible estructura alternativa de corrección dentro del marco neoliberal, definido como un modelo de "crecimiento con justicia". Este horizonte explícito en la conciencia de clase de la CUT fue imaginado por los partidos de la Concertación en su programa fundacional (Fazio, 1996: 32-33), como también fue trabajado posteriormente por intelectuales y economistas cercanos a esta coalición (CEPAL, 1992; Ffrench-Davis, 2003; Garretón, 2012).

Al examinar así, punto a punto, la influencia ideológica y política de la Concertación sobre el movimiento de trabajadores, parece una simple correa de transmisión. Y aunque es posible que algo de eso haya existido, sería una visión simplista del proceso, especialmente en el contexto de los matices planteados por los trabajadores, e incluso las disputas que surgieron con los gobiernos de esta coalición.

Parece más explicativo sostener que la subordinación popular en el contexto de alta desigualdad se debe a que la adopción del sistema de valores dominante parafraseando la expresión de Parkin (1978)- que se produjo en el Partido Socialista y la Democracia Cristiana dejó a la clase trabajadora organizada sin un referente que le permita interpretar su situación en términos radicales. Más en profundidad, de acuerdo a las reflexiones de Honneth (2011) y Boltanski y Chiapello (2002), la renovación tendría como consecuencia la desvinculación de las experiencias de injusticia de una comprensión teórico-moral que realice el proceso de identificación y codificación, y comparación con otras estructuras sociales posibles, y que de hecho históricamente hicieron ambos partidos con las ideas de socialismo y comunitarismo.

De esta manera se puede argumentar que la comprensión teórico-moral orientada hacia la convergencia de clases presente en la conciencia hipoconflictiva, es consecuencia del proceso que viven los partidos que lideran las organizaciones de la clase trabajadora. Ello tendría como consecuencia el impedir que las demandas de justicia sean articuladas y expresadas políticamente. 


\section{Referencias}

Almeyda, C. (1986): Pensando a Chile. Santiago: Terranova.

Alvaredo, F. y otros, (2016): "Top incomes in Chile: a historic perspective of personale-income inequalities (1962-2014)", en Conferencia Internacional 2016 Desigualdades COES-LSE. Santiago, COES-LSE, pp. 468-502.

Álvarez, R., Pinto, J. y Valdivia, V. (2008): Su revolución contra nuestra revolución, Vol. II. Santiago, LOM.

Álvarez, R. (2010): "¿Represión o integración? La política sindical del régimen militar. 1973-1980", Historia, 43, pp. 325-355.

Alvear, F. (2013): Genealogía de una ruptura. Tesis de grado. Santiago, Departamento de sociología, Universidad de Chile.

Angelcos, N. y M. Pérez (2017): "De la “desaparición" a la reemergencia: Continuidades y rupturas del movimiento de pobladores en Chile", Latin American Research Review, (52).

Araya, R. (2014): "Cambios y continuidades en el movimiento sindical chileno en los años 80. El caso del Comando Nacional de Trabajadores", Historia (Santiago), pp. 1137.

Baño, R., (1985): Lo social y lo político. Santiago, FLACSO.

Boltanski, L. y É. Chiapello (2002): El nuevo espíritu del capitalismo. Madrid, AKAL.

Braverman, H. (1981): Trabajo y capital monopolista. México, D.F., Nuestro Tiempo.

CEPAL (1992): Equidad y transformación productiva. Santiago, CEPAL.

Cury, M. (2018): El Protagonismo popular chileno. Experiencias de clase y movimiento sociales en la construcción del socialismo, 1964-1973. Santiago, LOM.

De La Maza, G. (2002): "Los movimientos sociales en la democratización de Chile", en P. Drake e I. Jaksic (comp.), El modelo chileno: democracia y desarrollo en los noventa. Santiago, LOM.

De la Maza, G. y Garcés, M. (1985): La explosión de las mayorías. Protesta Nacional 1983-1984. Santiago, ECO. 
Drake, P. (2003): "El movimiento obrero en Chile: de la Unidad Popular a la Concertación", Revista de Ciencia Política, 23(2), pp. 148-158.

Espinoza, V. (2012): El reclamo chileno contra la desigualdad de ingresos. Explicaciones, justificaciones y relatos, Izquierdas, pp. 1-25.

Faletto, E. y E. Ruiz (1970): Conflicto político y estructura social, en Chile Hoy. México/Santiago, Siglo XXI, pp. 213-254.

Fazio, H. (1996): El programa abandonado: balance económico social del gobierno de Aylwin. Santiago, LOM.

Ffrench-Davis, R. (2003): Entre el neoliberalismo y el crecimiento con equidad. Santiago, LOM.

Foxley, A. (1985): Para una democracia estable. Santiago, Editorial Aconcagua.

Frias, P. (2008): Desafíos del sindicalismo en los inicios del siglo XXI. Santiago, Clacso.

Garcés, M. (2003): Crisis social y motines populares en el 1900. Santiago, LOM.

Garcés, M. (2013): "Las luchas urbanas y la política chilena", Trashumante. Revista Americana de Historia Social (1), pp. 74-95.

Garretón, M. A. (2012): Neoliberalismo corregido y progresismo limitado. Santiago, ARCIS-CLACSO-PROSPAL.

Gaudichaud, F. (2005): "Construyendo "Poder Popular": El movimiento sindical, la CUT y las luchas obreras en el periodo de la Unidad Popular", en J. Pinto (ed.), Cuando hicimos historia. La experiencia de la Unidad Popular. Santiago, LOM, pp. 81105.

Giddens, A. (1996): La estructura de clases en las sociedades avanzadas. Madrid, Alianza Editorial.

Goldthorpe, J. y Erikson, R. (1992): The constant flux. Oxford, Claredon Press.

Hipsher, P. (1996): "Democratization and the Decline of Urban Social Movements in Chile and Spain", Comparative Politics, 28, pp. 173-197.

Honneth, A. (2011): La sociedad del desprecio. Madrid, Editorial TROTT. 
ICHEH (2003): ABC: El pensamiento político de la Democracia Cristiana. Santiago, ICEH.

Iglesias, M. (2007): El movimiento de pobladores contra la dictadura. Santiago, Ediciones Radio Universidad de Chile.

Instituto de Estudios Políticos del PDC (1962): El ABC de la Democracia Cristiana. Concepción, Instituto de Estudios Políticos.

Julián, D. (2014): "Legados del momento socialista en Chile: Una mirada al sindicalismo en los gobiernos de Lagos y Bachelet (2000-2010)". Teoría e sociedade, 22, pp. 118-140.

Katznelson, I. (1986): "Working-class formation: constructing cases and comparisons", en I. Katznelson y A. R. Zolberg (eds.), Working-class formation: nineteenth-century patterns in Western Europe and United States. Princeton, Princeton University Press, pp. 3-41.

Larrañaga, O. (2001): Distribución de Ingresos en Chile: 1958 - 2001. Documento de Trabajo №178. Departamento de Economía.

Lockwood, D. (1958): The Blackcoated Worker. A Study in Class Consciousness. Londres, Allen y Unwin.

Lukács, G. (1978): Historia y conciencia de clase. México, Grijalbo.

Mann, M. (1973): Consciousness and Action among the Western Working Class, Londres, Macmillan.

Manzano, C. (2014): La asamblea de la civilidad. Santiago, Londres 38.

Marx, K. y Engels, F. (1974): La ideología alemana. Barcelona, Coedición Grijalbo y Pueblos Unidos.

Marx, K. (1987): La miseria de la filosofía. México, Siglo XXI.

Ministerio de Desarrollo Social (2012): Distribución del Ingreso. Casen 2011. Santiago, Ministerio de Desarrollo Social.

Moulián, T. (1993): "El marxismo en Chile: producción y utilización", en VV.AA., Paradigmas de conocimiento y práctica social en Chile. Santiago, FLACSO. 
Moulián, T. (1997): Chile actual. Anatomía de un mito. Santiago, LOM.

Muñoz, M. (2012): "Plan Laboral y reformas post dictatoriales", Revista ICAL, 14, pp. 21-50.

Osorio, S. y F. Gaudichaud (2016): "Los caminos del movimiento sindical ante la democracia neoliberal y el legado de la dictadura, 1990-2015", en A. Pinol Bazzi (ed.), Democracia versus neoliberalismo. 25 Años de Neoliberalismo en Chile Santiago, ICAL, pp. 236-258.

Osorio, S. (2015): Trayectoria y cambios en la política del movimiento sindical en Chile, 1990-2010. Tesis para optar al grado de Magíster en Historia, Universidad de Santiago de Chile, Santiago.

Oxhorn, P. (1994): "Where did All the Protesters Go?: Popular Mobilization and the Transition to Democracy in Chile", Latin American Perspectives, 21, pp. 49-68.

Paley, J. (2001): Marketing Democracy: Power and Social Movements in PostDictatorship Chile. Berkeley, University of California Press.

Parkin, F. (1978): Orden político y desigualdades de clase. Madrid, Debate.

Poulantzas, N. (1971): Fascismo y dictadura. México D.F., Siglo XXI.

Poulantzas, N. (1998): La crisis de las dictaduras. México D.F., Siglo XXI.

Poulantzas, N. (2005): Las clases sociales en el capitalismo actual. México D.F., Siglo XXI.

Przeworski (1988): Capitalismo y socialdemocracia. Madrid, Alianza Editorial.

Raczynski, D. (1995): "Focalización de programas sociales", en C. Pizarro, D. Raczynski y J. Vial, Políticas económicas y Sociales en el Chile Democrático. Santiago, CIEPLAN, pp. 217-255.

Roberts, K. (2002): "Social Inequalities Without Class Cleavages in Latin America's Neoliberal Era", Studies in Comparative International Development, 36, pp. 3-33.

Rojas, L. (2011): De la rebelión popular a la sublevación imaginada. Santiago, LOM.

Ruiz, C. y G. Boccardo (2014): Los chilenos bajo el neoliberalismo. Santiago, NODO XXI y El Desconcierto. 
Salazar, G. (2010): Conversaciones con Carlos Altamirano. Memorias críticas. Santiago, Debate.

Thompson, E. (2012): La formación de la clase obrera en Inglaterra. Madrid, Capitán Swing.

Torcal, M. y S. Mainwaring (2003): "El conflicto democracia/autoritarismo y sus bases sociales en Chile, 1973-1995: un ejemplo de redefinición política de un cleavage", Revista Española de Investigaciones Sociológicas, pp. 51-82.

Valenzuela, E. (2014): La conversión de los socialistas chilenos. Santiago, El Desconcierto.

Wright, E. (1993): Reflexionando una vez más sobre el concepto de estructura de clases. Zona Abierta, pp. 17-125.

Wright, E. (1994): Clases. Madrid, Siglo XXI.

Wright, E. (2000): Class Counts, student edition, Cambridge University Press.

Zapata, F. (2004): "De la democracia representativa a la democracia "protegida". Movimiento obrero y sistema político en Chile". Enfoques, 2(3), pp. 25-55.

Fecha de recepción: 2 de mayo de 2021

Fecha de aceptación: 9 de julio de 2021 